Jurnal Riset Agama

Volume 1, Nomor 2 (Agustus 2021): 481-491

DOI: $10.15575 /$ jra.v1i2.14766

https://journal.uinsgd.ac.id/index.php/jra

\title{
Transaksi Dropshipper Melalui E-Commerce: Studi Takhrij dan Syarah Hadis
}

\author{
Nabila Fairuz Putri Kamilah \\ Jurusan Ilmu Al-Qur'an dan Tafsir, Fakultas Ushuluddin \\ UIN Sunan Gunung Djati Bandung \\ nabilafairuzp@gmail.com
}

\begin{abstract}
This study aims to analyze the hadith about dropshipper transactions through e-commerce. This study uses a qualitative approach that emphasizes literature study through the takhrij and syarah hadith methods with contemporary analysis. The results of this study found that the quality status of this dropshipper transaction was considered authentic based on the takhrij hadith. Syarah hadith shows that dropshipper transactions if a salam contract is used, then the transaction is valid and may be carried out with an agreement that has been made with the supplier. However, if the seller does not mention himself as a dropshipper then it is prohibited, because there is no agreement and there is an element of fraud (gharrar). This study concludes that the hadith about dropshipper transactions through e-commerce is acceptable (maqbul) so that it can be used as evidence for Islamic practice. This study recommends that a review be carried out through the approach of hadith science and economics related to dropshipper transactions in terms of processes and objects if you want to transact as a dropshipper with sharia provisions.
\end{abstract}

Keywords: Buy and Sell; Dropshipping; E-Commerce; Transaction.

\begin{abstract}
Abstrak
Penelitian ini bertujuan untuk menganalisis hadis tentang transaksi dropshipper melalui e-commerce. Penelitian ini menggunakan pendekatan kualitatif yang menekankan pada studi pustaka melalui metode takhrij dan syarah hadis dengan analisis kontemporer. Hasil penelitian ini menemukan bahwa status kualitas hadis transaksi dropshipper ini dinilai shahih berdasarkan takhrij hadis. Syarah hadis menunjukkan bahwa transaksi dropshipper jika digunakan akad salam maka transaksi tersebut sah dan boleh dilakukan dengan kesepakatan yang telah dibuat dengan supplier. Namun jika penjual tidak
\end{abstract}


Jurnal Riset Agama, Volume 1, Nomor 2 (Agustus 2021): 458-469

Nabila Fairuz Putri Kamilah/Transaksi Dropshipper Melalui E-Commerce: Studi Takhrij dan Syarah Hadis

menyebutkan dirinya sebagai dropshipper maka itu dilarang, karena belum ada kesepakatan dan ada unsur penipuan (gharrar). Penelitian ini menyimpulkan bahwa hadis tentang transaksi droppshipper melalui e-commerce dapat diterima (maqbul) sehingga dapat digunakan sebagai hujjah amalan Islam. Penelitian ini merekomendasikan agar dilakukan kajian kembali melalui pendekatan ilmu hadis dan ilmu ekonomi terkait transaksi dropshipper dari segi proses dan objek jika ingin bertransaksi sebagai dropshipper dengan ketentuan syariah.

Kata kunci: E-Commerce; Dropship; Jual Beli; Transaksi.

\section{Pendahuluan}

Kemajuan teknologi di era globalisasi ini menjadikan sebuah cerminan baru dalam dunia bisnis, salah satunya dengan adanya perputaran transaksi jual beli yang bermula dengan offline beralih ke transaksi online dengan menggunakan media internet atau disebut dengan e-commerce (electronic commerce) (Bariroh, 2016). Terdapat beragam fasilitas yang disuguhkan oleh e-commerce, di antaranya kemudahan dalam bertransaksi dengan mengefisiensikan waktu tanpa harus bertatap muka dan juga tenaga (Bariroh, 2016). Bentuk dari salah satu transaksi online yaitu sistem dropshipping (Tektona, 2021). Dropshipping merupakan suatu transaksi (Iswidharmanjaya, 2012) jual beli tanpa wajib mempunyai barang yang akan dijual (Pitriani \& Purnama, 2020). Dengan transaksi dropshipping, seseorang dapat menjual aneka macam produk dagangan pada konsumen tanpa perlu adanya modal, tetapi hanya dengan mempublikasikan katalog produk dari agen (Tektona, 2021). Namun sistem dropshipping ini masih menjadi peredebatan di kalangan para ulama terkait boleh atau tidaknya untuk dipergunakan (Nubahai, 2019). Beberapa ulama yang melarang menggunakan sistem dropshipping ini tercantum pada hadis riwayat Abu Dawud No. 3040. Hal tersebut berkaitan dengan salah satu syarat akad jual beli yang belum terpenuhi yakni tidak mempunyai hak kepemilikan dari produk barang yang akan dijual (Novitasari, 2020). Sistem ini mempunyai kelemahan terhadap barang yang hendak dijual, baik dari foto atau spesifikasi produk yang tidak sesuai dengan katalog atau terkait proses transaksi dan serah terima barang (Tektona, 2021). Oleh karena itu, melihat dari fenomena yang sedang populer di kalangan dunia bisnis ini penulis tertarik untuk mengkaji kembali transaksi dropshipping dengan landasan hadis menggunakan teori ilmu hadis dengan dilengkapi syarah. Sehingga dapat diketahui bagaimana transaksi jual beli yang dianjurkan oleh Rasulullah Saw. 
Jurnal Riset Agama, Volume 1, Nomor 2 (Agustus 2021): 458-469

Nabila Fairuz Putri Kamilah/Transaksi Dropshipper Melalui E-Commerce: Studi Takhrij dan Syarah Hadis

Beberapa peneliti telah melakukan penelitian terkait fenomena transaksi dropshipping yang sedang marak di kalangan dunia bisnis. Di antaranya yakni Novitasari (2020), "Analisis Transaksi Dropshipping dalam Perspektif Ekonomi Syariah," Jurnal Al-Iqtishad: Jurnal Ekonomi Syariah. Penelitian ini membahas tentang apakah sistem transaksi dropshipping ini sudah sesuai dengan prinsip ekonomi syariah sehingga para pendiri usaha kecil maupun besar dapat memahami sistem tersebut termasuk kepada konsep syariah atau tidak. Penelitian ini menggunakan metode deskriptif dengan mengumpulkan penelitian terdahulu dan dianalisis kembali untuk mengetahui sistem transaksi dropshipping yang sedang marak di kalangan masyarakat. Hasil dari beberapa penelitian sebelumnya maka dapat disimpulkan bahwa sistem transaksi dropshipping belum dinyatakan sepenuhnya sesuai dengan konsep syariah. Karena ada beberapa hal yang membuat sistem ini belum termasuk dalam konsep syariah, salah satunya adalah tidak sesuai dengan rukun dan syarat jual beli dikarenakan barang yang hendak dijual bukan milik sendiri (Novitasari, 2020). Tektona, Rahmadi Indra (2021), "Jual Beli Online Dropshipping dalam Perspektif Maqashid Syari'ah," Jurnal Ahkam. Penelitian ini mengkaji tentang penjelasan secara lengkap dan sistematis dengan beragam peraturan, analisis bahan hukum serta memprediksi perkembangan norma-norma hukum terkait transaksi drophipping yang akan menjadi transaksi yang cukup panjang penggunaannya. Penelitian ini menggunakan penelitian hukum normatif dengan menggunakan dokumen hukum perundang-undangan dan bahan pustaka menurut pandangan hukum Islam. Hasil dari penelitian ini adalah sistem transaksi online dengan dropshipping ini tidak dilarang dalam Islam, karena pada kaidah umum fiqih muamalah yang mengatakan bahwa semua bentuk muamalah diperbolehkan kecuali ada dalil yang mengharamkannya. Sistem dropshipping ini menggunakan dua akad, yaitu akad salam dan akad wakalah (Tektona, 2021). Firmansyah, M.D. (2021), "Tanggung Jawab Dropshipper dalam Transaksi E-Commerce dengan Sitem Dropshipping dalam Perspektif Hukum di Indonesia (Studi di Akun Instagram yukngediskon)," Universitas Mataram. Penelitian ini mengkaji dan menganalisa perlindungan konsumen dalam transaksi e-commerce menurut ketentuan peraturan yang berlaku. Penelitian ini menggunakan metode hukum normatif empiris yang menggunakan pendekatan perundang-undangan, sosiologis dan koseptual. Hasil dari penelitian ini dapat disimpulkan bahwa bentuk perlindungan hukum dalam transaksi drophipping di yukngediskon dilakukan secara preventif dan represif serta Dropshipper bertanggung jawab terkait kerugian yang dialami konsumen akibat penjualan suatu produk (Firmansyah, 2021). 
Jurnal Riset Agama, Volume 1, Nomor 2 (Agustus 2021): 458-469

Nabila Fairuz Putri Kamilah/Transaksi Dropshipper Melalui E-Commerce: Studi Takhrij dan Syarah Hadis

Dengan adanya penelitian terdahulu mengenai transaksi dropshipping yang telah diuraikan pada tinjauan pustaka sangat membantu dalam penyusunan kerangka berpikir penelitian ini. Dalam penelitian ini penulis akan mengkaji lebih dalam mengenai fenomena yang sedang marak di dalam dunia bisnis yaitu transaksi dengan sistem dropshipping. Seluruh umat Islam mengetahui bahwa hadis merupakan sumber ajaran Islam kedua setelah Al-Qur'an. Dalam memahami isi hadis terdapat banyak perbedaan pendapat sehingga perlu dikaji kembali, baik dari segi sanad ataupun isi hadis tersebut. Dalam mengkaji kembali hadis tersebut perlu menggunakan metode yang disebut dengan takhrij (Qomarullah, 2016). Takhrij menurut Mahmud al-Thahhan merupakan metode penelusuran tempat hadis dari sumber-sumber yang asli dalam menyebutkan hadis beserta sanadnya, lalu dikaji kembali kualitas hadisnya. Sedangkan syarah hadis yakni penjelasan yang berkaitan dengan hadis, yakni cara untuk menafsirkan makna yang terkandung di dalam hadis (Darmalaksana, 2020c). Hadis tentang "transaksi drophipping" ditemukan beberapa yang berkaitan dengan transaksi menggunakan akad yang berbeda-beda serta larangan bertransaksi dengan sistem dropshipping. Tentunya menjadi sebuah keharusan bagi peneliti untuk mengkaji kembali isi hadis tersebut. Hal ini agar dapat diketahui bahwa hadis tersebut datang dari sabda Rasulullah Saw ataukah bukan, serta memberikan kemudahan bagi siapapun yang ingin mengamalkannya setelah tahu bahwa hadis tersebut termasuk maqbul (dapat diterima) ataukah mardud (tertolak) (Qomarullah, 2016).

Berdasarkan pemaparan di atas, penulis berupaya untuk menyusun formula penelitian yang terdiri dari rumusan masalah penelitian, pertanyaan utama terkait penelitian, dan tujuan penelitian (Darmalaksana, 2020a). Rumusan masalah dalam penelitian ini yaitu terdapat syarah hadis terkait transaksi dropshipping melalui E-Commerce. Pertanyaan utama penelitian ini yaitu bagaimana syarah hadis terkait transaksi dropshipping melalui E-Commerce. Adapun pertanyaan penelitian secara terperinci yaitu bagaimana teks hadis tentang transaksi dropshipping, bagaimana kualitas hadis tentang transaksi dropshipping melalui E-Commerce, dan bagaimana syarah hadis tentang transaksi dropshipping melalui E-Commerce. Tujuan penelitian ini yakni membahas syarah hadis tentang transaksi dropshipping berkenaan dengan fenomena yang sedang marak dalam dunia bisnis terutama bisnis online di kalangan masyarakat. Diharapkan dengan adanya penelitian ini dapat memberikan pandangan kepada masyarakat terhadap fenomena transaksi dropshipping dan mengetahui bagaimana transaksi jual beli yang dianjurkan oleh Rasulullah Saw. 
Jurnal Riset Agama, Volume 1, Nomor 2 (Agustus 2021): 458-469

Nabila Fairuz Putri Kamilah/Transaksi Dropshipper Melalui E-Commerce: Studi Takhrij dan Syarah Hadis

\section{Metode Penelitian}

Penelitian ini menggunakan pendekatan kualitatif melalui studi pustaka (Darmalaksana, 2020b). Penelitian ini menerapkan metode takhrij dan syarah hadis (Darmalaksana, 2020d). Adapun interprestasi digunakan analisis kontemporer (Darmalaksana, 2020c).

\section{Hasil dan Pembahasan}

Hasil penelitian dan pembahasan disajikan dalam beberapa hal sebagai berikut ini.

\section{Teks Hadis Transaksi Dropshipping}

Berdasarkan pencarian hadis tentang transaksi dropshipping melalui aplikasi Ensiklopedia Hadits Kitab 9 Imam (Saltanera, 2015) penulis menemukan beberapa hadits yang bersangkutan, namun yang akan menjadi pembahasan penelitian ini yaitu hadits riwayat Abu Dawud No. 3040 Kitab Ijarah Bab Menjual Sesuatu Yang Bukan Miliknya, redaksinya sebagai berikut:

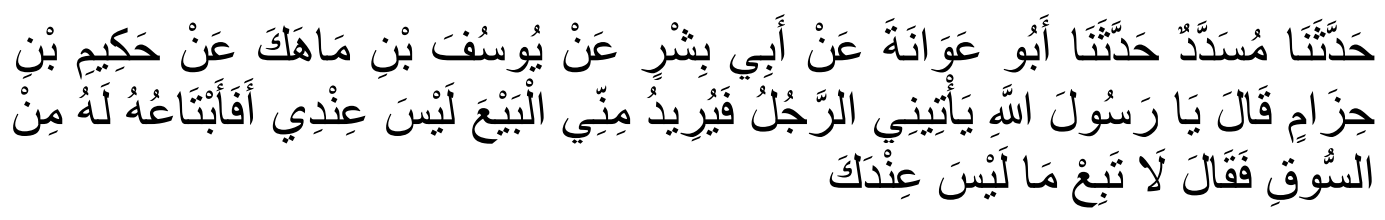

Artinya: Telah menceritakan kepada kami Musaddad telah menceritakan kepada kami Abu 'Awanah dari Abu Bisyr dari Yusuf bin Mahik dari Hakim bin Hizam ia berkata, "Wahai Rasulullah, seorang lakilaki datang kepadaku ingin membeli sesuatu yang tidak aku miliki, apakah boleh aku membelikan untuknya dari pasar? Beliau bersabda, "Janganlah engkau menjual apa yang tidak engkau miliki!" (HR. Abu Dawud No. 3040).

\section{Daftar Rawi dan Sanad Hadis Transaksi Dropshipping}

Takhrij Hadits terkait transaksi dropshipping disajikan dalam bentuk tabel sebagai berikut. 
Jurnal Riset Agama, Volume 1, Nomor 2 (Agustus 2021): 458-469

Nabila Fairuz Putri Kamilah/Transaksi Dropshipper Melalui E-Commerce: Studi Takhrij dan Syarah Hadis

Tabel 1. Daftar Rawi Sanad

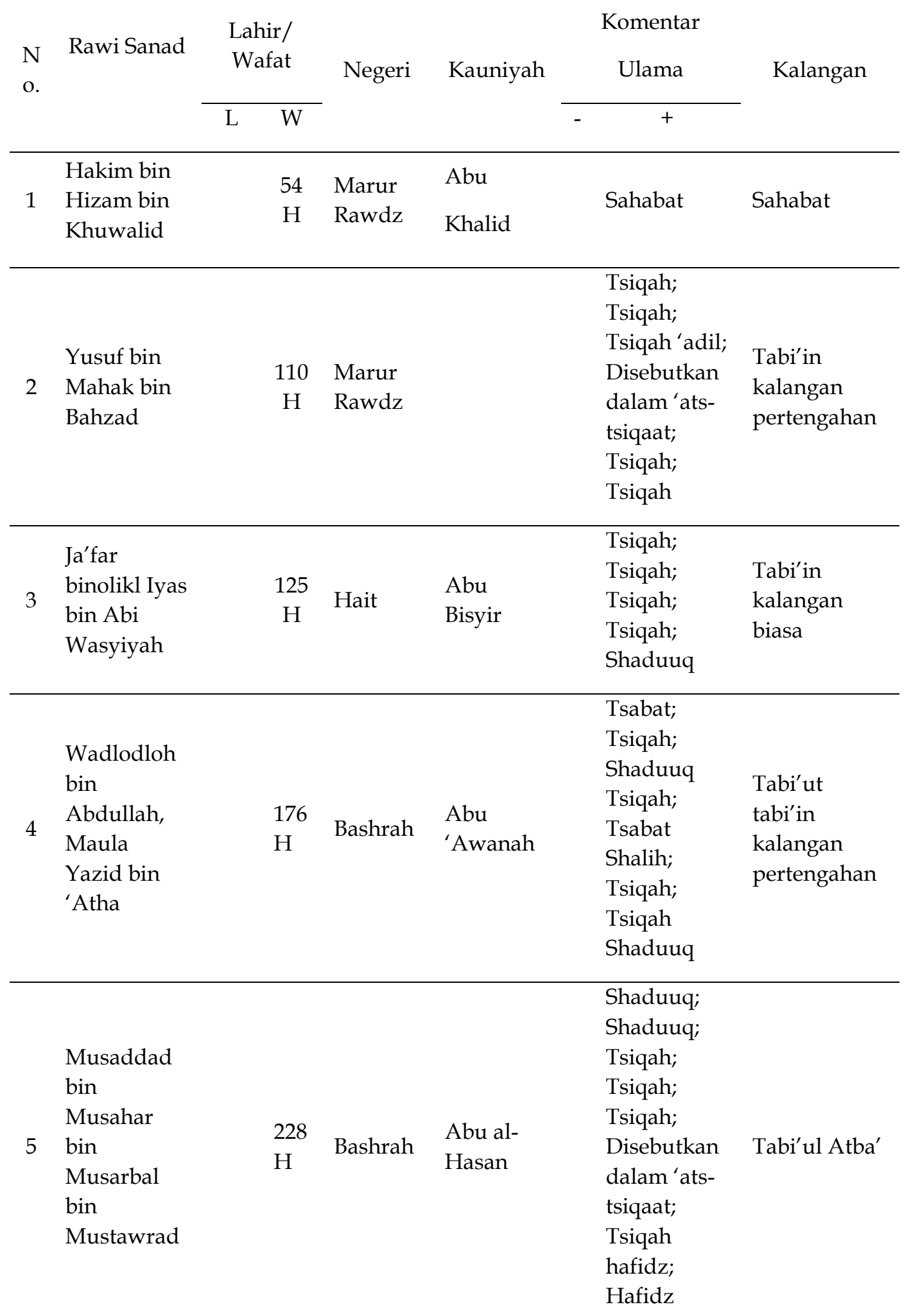


Jurnal Riset Agama, Volume 1, Nomor 2 (Agustus 2021): 458-469

Nabila Fairuz Putri Kamilah/Transaksi Dropshipper Melalui E-Commerce: Studi Takhrij dan Syarah Hadis

$\begin{array}{lccclll}\text { Sulaiman } & & & & & & \\ \text { bin al- } & & & & & \\ \text { Asy'ats bin } & 202 & 275 & \text { Bashrah } & \text { Abu } & \text { Imam } & \text { Mudawwin } \\ \text { Ishaq bin } & \text { H } & \text { H } & & & \text { Hadis } & \\ \text { Basyir bin } & & & & & & \\ \text { Syiddad } & & & & & \end{array}$

Tabel 1 merupakan daftar rawi dan sanad hadits riwayat Imam Abu Dawud No. 3040 tentang transaksi dropshipping Kitab Ijarah Bab Menjual Sesuatu Yang Bukan Miliknya dan pada versi Baitul Afkar ad-Dauliah No. 3503. Pada tabel di atas terdapat rawi sanad, tahun lahir dan wafat, negeri, nama panggilan (kuniyah), komentar ulama dan juga kalangannya. Hadis ini diriwayatkan oleh 6 (enam) perawi diawali dari seorang sahabat sampai mudawwin yakni Sulaiman bin al-Asy'ats bin Basyir bin Syiddad atau dikenal sebagai Imam Abu Dawud. Dari 5 (lima) perawi di atas, hanya ada satu yang tidak diketahui nama panggilan (kuniyah) yaitu Yusuf bin Mahak bin Bahzad. Rawi pertama dari teks hadis ini yaitu Hakim bin Hizam bin Khuwalid. Sedangkan sanad pertama dari hadis ini yaitu Sulaiman bin al-Asy'ats bin Ishaq bin Basyir bin Syiddad. Berdasarkan ilmu hadis, rawi pertama ialah sanad terakhir sedangkan rawi terakhir ialah sanad pertama (Darmalaksana, 2021b).

\section{Kualitas Hadis Transaksi Dropshipping}

Syarah hadits dikatakan berkualitas sahih apabila rawi adil dan dhabit, sanad bersambung (muttasil), matan hadits tidak janggal, dan matan hadits tidak cacat (Darmalaksana, 2020d). Pada tabel 1 terlihat banyak para ulama yang memberikan komentar positif (ta'dil) terhadap para rawi dengan memberi komentar tsiqah. Rawi yang dinilai tsiqah berarti ia ialah orang yang dapat dipercaya dari segi adil dan dhabit (kuat hapalannya), karena tsiqah merupakan gabungan dari keduanya (adil dan dhabit) (Nadhiran, 2014). Rawi dikatakan tsiqah berarti ia merupakan orang terpercaya dari segi adil dan dhabit (kuat hapalannya). Selain itu, para ulama memberikan komentar shaduuq, hafidz dan tsabat. Hal ini dapat terlihat jelas pada tabel bahwa tidak ada satupun komentar para ulama yang negatif terhadap para rawi. Maka dengan demikian, dapat disimpulkan bahwa rawi dalam jalur sanad ini seluruhnya adil dan dhabit yang dapat mempengaruhi kualitas sanad hadis.

Persambungan sanad dijadikan oleh para ulama sebagai salah satu tolak ukur ke-shahih-an suatu hadits (Anshori, 2016). Syarat sanad sanad bersambung yaitu adanya guru yang menyampaikan hadits dan murid yang menerima hadits saling bertemu yaitu guru dan murid hidup sezaman atau satu profesi sebagai muhadditsin (Darmalaksana, 2018, 
Jurnal Riset Agama, Volume 1, Nomor 2 (Agustus 2021): 458-469

Nabila Fairuz Putri Kamilah/Transaksi Dropshipper Melalui E-Commerce: Studi Takhrij dan Syarah Hadis

2020d, 2021b). Guru dan murid dikatakan bertemu apabila mereka sezaman atau berada di suatu wilayah, dimana hal itu dilihat dari tahun lahir dan wafat para rawi (Darmalaksana, 2018, 2020d, 2021b).

Apabila para perawi tidak diketahui tahun lahir dan wafat, maka para rawi dapat diasumsikan rata-rata berusia kurang lebih 90 tahun (Darmalaksana, 2018, 2020d, 2021a, 2021b). Apabila melihat pada tabel di atas, maka beberapa rawi tidak diketahui tahun lahirnya, namun dapat diperkirakan para rawi bertemu antara guru dengan murid. Dengan demikian, sanad hadis riwayat Abu Dawud No. 3040 bersambung dalam istilah lain yakni ittishalussanad (Anshori, 2016).

Selain dilihat dari aspek penilaian rawi dan sanad, kualitas hadits ditentukan dari segi matan dengan syarat terhindar dari syadz (kejanggalan) dan 'illat (cacat) (Devi, 2020). Pada teks hadits riwayat Abu Dawud No. 3040 tidak terdapat kejanggalan (syadz) dan cacat ('illat), maka dapat dikatakan bahwa hadis ini sebagai hadits yang shahih. Dalam hadis ini disebutkan bahwa seseorang dilarang menjual apapun yang bukan miliknya, tentunya jika ia menjual maka tidak sesuai dengan syarat jual beli. Dari awal sampai akhir sanad ialah tersambung. Dengan adanya persambungan ini tentunya dapat dilihat dari segi kualitasnya ialah shahih. Sedangkan dari segi matan, tidak ada yang bertolak belakang dengan kesahihan matan.

\section{Syarah Hadis Transaksi Dropshipping}

Syarah ialah penjelasan tentang hadis, begitu pula syarah yang berkaitan dengan hadis merupakan usaha menafsirkan makna yang ada dibalik teks hadis (Darmalaksana, 2020c). Hadis yang dapat diamalkan dan dapat diterima melalui takhrij (Darmalaksana, 2018). Menurut takhrij didapati status shahih baik dari segi bersambungnya sanad, 'adil, dan dhabit para perawi serta matan yang tidak adanya syadz dan 'illat.

Hadis riwayat Abu Dawud No. 3040 disebutkan bahwa ketika seseorang datang menemui Rasulullah Saw dan bertanya bolehkah membeli sesuatu yang tidak ia miliki dan membelikannya untuknya dari pasar, Beliau bersabda, "Janganlah engkau menjual apa yang tidak engkau punya." Redaksi teks hadis ini terlihat serupa dengan hadis riwayat Tirmidzi No. 1153, Nasa'i No. 4534, dan Ibnu Majah No. 2178 \& 2179 (Saltanera, 2015). Semua matan hadis memiliki sedikit perbedaan dari segi perawi, namun perbedaan ini tidak mengenyampingkan makna kandungan teks haidts, akan tetapi menjadi saling menguatkan.

Imam Muhammad Syams al-Haq menjelaskan bahwa hadis tersebut merupakan orang-orang yang menjual tanpa adanya barang atau produk, maka sebelum adanya perjanjian (akad) yang jelas itu tidak diperbolehkan. Dan jika itu (barang) bukan miliknya, dalam akad ini tidak 
Jurnal Riset Agama, Volume 1, Nomor 2 (Agustus 2021): 458-469

Nabila Fairuz Putri Kamilah/Transaksi Dropshipper Melalui E-Commerce: Studi Takhrij dan Syarah Hadis

boleh diperjualbelikan, karena barang yang akan dijual belum dimilikinya. Dalam hal ini, السُّوقِ مِنْ لَهُ أَفَأَبَتَاعُهُ (bolehkah aku menjualnya di pasar) sedangkan dalam riwayat Imam Tirmidzi disebutkan dengan penambahan hamzah istifham sehingga maknanya menjadi (apakah aku boleh membelikannya di pasar). Lalu, عَنْدَكَ لَيْسَ مَا تَبْعْ لََ فَقَالَ (Nabi saw bersabda: Janganlah kamu menjual aoa yang tidak kamu miliki), maksudnya yaitu sesuatu yang tidak ada dalam perjanjian atau kesepakatan hak si penjual. Jual beli yang dimaksud adalah $b a^{\prime} i$ al-a'yan (menjual barang yang sudah ditentukan), dari syarh ini disimpulkan bahwa memesan barang dagangan yang belum dimiliki (belum tersedia) ada dua macam. Pertama, memesan barang berdasarkan kriteria. Kedua, memesan barang yang sudah ditentukan.

Sementara itu, عَنْدَكَّ كَيَسَ مَا (barang yang bukan kamu miliki), maksudnya yang merusak jual beli ini yakni jual beli barang yang belum dipindahkan atau yang tidak punya hak kepemilikan sebagaimana dijelaskan pada Kitab 'Aun al-Ma'bud ' ala Syarh Sunan Abi Daud (Hafizzullah, 2018).

Faishal, al-Baghhawi menyebutkan bahwa larangan dalam hadis ini adalah larangan menjual barang-barang yang tidak menjadi milik, adapun menjual barang yang dalam tanggungannya telah disebutkan, maka transaksi ini boleh dilakukan dengan pembayaran terlebih dahulu dan menjadi hak milik penjual terlebih dahulu dengan menggunakan akad salam dan juga dengan syarat-syarat tertentu (Khamidiyah, 2016).

Seperti yang telah diuraikan, dropshipping ialah transaksi dimana penjual menjualkan barang milik orang lain dengan menampilkan katalog dengan spesifikasi barang tersebut. Sementara, barang yang diproduksi, pengiriman, pengambilan foto untuk katalog semua ditanggung oleh agen atau supplier, sehingga transaksi dropshipping ini menandakan menjual barang yang bukan miliknya. Apabila transaksi dropshipping dikategorikan kepada jual beli akad salam, maka syarat-syaratnya harus terpenuhi. Salah satu syarat salam yang harus digarisbawahi yakni modal, uang, dan harga. Dan juga syarat salam yang lainnya yaitu harga harus jelas dan dibayar tunai telebih dahulu. Pembayaran yang disediakan oleh dropshipper ini biasanya diperbolehkannya dengan kredit atau mencicil. Jika transaksi ini menggunakan akad salam dan pembayarannya dengan mencicil, maka tidak sah, karena ini termasuk dalam jual beli dayn (hutang) (Khamidiyah, 2016).

\section{Kesimpulan}

Dropshipping merupakan suatu transaksi jual beli tanpa wajib mempunyai barang yang akan dijual. Dengan transaksi dropshipping, seseorang dapat menjual aneka macam produk dagangan pada konsumen 
Jurnal Riset Agama, Volume 1, Nomor 2 (Agustus 2021): 458-469

Nabila Fairuz Putri Kamilah/Transaksi Dropshipper Melalui E-Commerce: Studi Takhrij dan Syarah Hadis

tanpa perlu adanya modal, tetapi hanya dengan mempublikasikan katalog produk dari agen. Sistem ini mempunyai kelemahan terhadap barang yang hendak dijual, baik dari foto atau spesifikasi produk yang tidak sesuai dengan katalog atau terkait proses transaksi dan serah terima barang. Status hadis tentang transaksi dropshipper ini berkualitas shahih, baik dari segi matan maupun sanad. Dari syarah hadis menunjukan bahwa transaksi dropshipper jika menggunakan akad salam maka transaksi tersebut sah dan boleh dilakukan dengan kesepakatan yang telah dibuat dengan supplier. Namun jika penjual tidak menyebutkan dirinya sebagai dropshipper maka itu dilarang, karena belum ada kesepakatan dan ada unsur penipuan (gharrar). Terlebih semua resiko selama pengiriman produk hingga tiba di tangan pembeli menjadi sebuah tanggung jawab dropshipper bukan supplier, karena supplier mengirim barang atas nama dropshipper. Karena kandungan matan juga tidak bertentangan dengan hadis lain, maka hadis riwayat Abu Daud No. 3040 ini dapat dijadikan hujjah. Penelitian ini diharapkan memiliki implikasi manfaat bagi yang ingin melakukan transaksi dengan sistem dropshipping. Penelitian ini memiliki keterbatasan yaitu kurangnya penguasaan terhadap ilmu ekonomi syariah dan ilmu hadis. Sehingga perlu adanya penelitian lebih lanjut, terutama dari segi takhrij serta analisis sesuai dengan isu kontemporer. Penelitian ini merekomendasikan agar dilakukan penelitian kembali melalui pendekatan ilmu hadis dan ilmu ekonomi terkait transaksi dropshipper dari segi proses dan objek jika ingin bertransaksi sebagai dropshipper dengan ketentuan syariah.

\section{Daftar Pustaka}

Anshori, M. (2016). Kajian Ketersambungan Sanad (Ittişāl al-Sanad). Jurnal Living Hadis, 1(2), 294.

https:/ / doi.org/10.14421/livinghadis.2016.1123

Bariroh, M. (2016). Transaksi Jual Beli Dropshipping dalam Perspektif Fiqh Muamalah. Ahkam: Jurnal Hukum Islam, 4(2), 199-216. https:/ / doi.org/10.21274/ahkam.2016.4.2.199-216

Darmalaksana, W. (2018). Paradigma Pemikiran Hadis. JAQFI: Jurnal Aqidah Dan Filsafat Islam, 2(1), 95-106.

Darmalaksana, W. (2020a). Formula Penelitian Pengalaman Kelas Menulis. Jurnal Kelas Menulis UIN Sunan Gunung Djati Bandung. http://digilib.uinsgd.ac.id/32620/

Darmalaksana, W. (2020b). Metode Penelitian Kualitatif Studi Pustaka dan Studi Lapangan. Pre-Print Digital Library UIN Sunan Gunung Djati Bandung.

Darmalaksana, W. (2020c). Penelitian Metode Syarah Hadis Pendekatan Kontemporer: Sebuah Panduan Skripsi, Tesis, dan Disertasi. Diroyah: 
Jurnal Riset Agama, Volume 1, Nomor 2 (Agustus 2021): 458-469

Nabila Fairuz Putri Kamilah/Transaksi Dropshipper Melalui E-Commerce: Studi Takhrij dan Syarah Hadis

Jurnal Studi Ilmu Hadis, 5.

Darmalaksana, W. (2020d). Prosiding Proses Bisnis Validitas Hadis untuk Perancangan Aplikasi Metode Tahrij. Jurnal Ushuluddin UIN Sunan Gunung Djati Bandung, 1, 1-7.

Darmalaksana, W. (2021a). Herbal Tumbuhan Senna dalam Pengobatan Infeksi Covid-19: Studi Takhrij dan Syarah Hadis. Pre-Print Kelas Menulis UIN Sunan Gunung Djati Bandung, 19, 1-11.

Darmalaksana, W. (2021b). Kosmetik Halal sebagai Lifestyle untuk Kesehatan: Studi Takhrij Hadis dan Syarah Hadis. Pre-Print Kelas Menulis Sunan Gunung Djati Bandung, 148, 148-162.

Devi, A. D. (2020). Studi Kritik Matan Hadits. Jurnal Studi Ilmu Al-Qur'an Dan Al-Hadits, 14(2).

Firmansyah, M. D. (2021). Tanggung Jawab Dropshipper dalam Transaksi ECommerce dengan Sistem Dropshipping dalam Perspektif Hukum di Indonersia (Vol. 7). Universitas Mataram.

Hafizzullah, S. A. (2018). Kitab 'Aun al-Ma'bud' ala Syarh Sunan Abi Daud. Al-Fuad: Jurnal Sosial Keagamaan, 2(1).

Iswidharmanjaya, D. (2012). Dropshipping Cara Mudah Bisnis Online. PT. Elex Media Komputindo.

Khamidiyah, N. (2016). Dropshipping dalam Hadis (Studi Hadis Larangan Menjual Barang yang Bukan Miliknya dalam Sunan Tirmidhi Nomor 1236). UIN Sunan Ampel Surabaya.

Nadhiran, H. (2014). Kritik Sanad Hadis: Telaah Metodologis. Jurnal Ilmu Agama: Mengkaji Doktrin, Pemikiran, Dan Fenomena, 15(1), 91-109.

Novitasari, N. (2020). Analisis Transaksi Dropshipping dalam Persepektif Ekonomi Syariah. Jurnal Al-Iqtishad, 2(01), 56-68.

Nubahai, L. (2019). Konsep Jual Beli Model Dropshipping Prespektif Ekonomi Islam. MISYKAT: Jurnal Ilmu-Ilmu Al-Quran, Hadits, Syari'ah Dan Tarbiyah, 4(1), 79. https:/ / doi.org/10.33511/misykat.v4n1.79-100

Pitriani, E., \& Purnama, D. (2020). Dropshipping dalam Perspektif Konsep Jual Beli Islam. Jurnal Ekonomi Dan Perbankan Syariah, 3(2), 87-104. https://doi.org/10.46899/jeps.v3i2.162

Qomarullah, M. (2016). Metode Takhrij Hadits dalam Menakar Hadits Nabi. El-Ghiroh, XI(2), 23-34.

Saltanera. (2015). Ensiklopedi Hadits Kitab 9 Imam. Lembaga Ilmu Dan Dakwah Publikasi Sarana Keagamaan, Lidwa Pusaka.

https:/ / store.lidwa.com/get/

Tektona, R. I. (2021). Jual Beli Online Dropshipping dalam Perspektif Maqashid Syari'ah. Ahkkam, 9, 81-104. 